\title{
Analyzing on Relationship of Logistics and Non-Logistics Based on SLP Wen-Yu MOU ${ }^{a^{*}}$, Peng-Hui SONG ${ }^{\text {b }}$, Shi CHEN ${ }^{\mathrm{c}}$ \\ ${ }^{1}$ Shandong Jiaotong University, Ji'nan 250357, China \\ a'KSTG4414102@163.com, bfei13031742917@163.com, ' $1669908291 @ 163 . c o m$
}

Keywords: SLP, Logistics relationship, Non logistics relationship, Analyzing.

\begin{abstract}
The SLP about multimodal transport facilities layout planning issues in logistics park. The article mainly analyses both logistics and non-logistics relationship in SLP methods, and also comprehensive relationship between these two. Thus solving relative problems.
\end{abstract}

\section{Introduction}

In 1961, the United States Richard Muther used the concept of systematic engineering and systematic analysis method and thereby putting forward the systematic Layout design method SLP (Systematic Layout Planning). By using the hierarchical representation method about the mutual relationship among the operating units, the facility layout problem, which is at qualitative stage, becomes to quantitative stage. The main task of the SLP method is to make an analysis of the relationship between the units including the relationship between logistics and non Logistics. In the end, we can get operation unit relationship table.

\section{Analysis of the Basic Elements of in SLP}

Initially, SLP is mainly used in factory designing area. According to the systematic layout design, it assumes that Product (P), Quantity(Q), Route(R), Service(S) and Time(T) are basic elements, and they are considered as the basic starting point of the layout design work. However, time is not usually considered in real production. While technology plays a significant role in SLP method[1,2].

\section{Logistics Object $\mathbf{P}$}

Multimodal transport facilities layout planning In the logistics park, the nature of the service object not only decides logistics carrying equipment, storage condition and so on. At the same time, it also affects the layout of multimodal transport facilities in Logistics Park.

\section{Logistics Quantity Q}

Based on the distribution of logistics objects, the quantity of work can be calculated for multimodal transport facilities category of logistics objects in logistics park. It determines the size and quantity of logistics facilities. The determination of logistics quantity needs to predict the future logistics quantity based on the existing demand. Therefore, $\mathrm{Q}$ is a predicted logistics quantity within a certain period based on the actual data[3].

\section{Logistics Operation Route $\mathbf{R}$}

Logistics operation route $\mathrm{R}$ refers to the flow of logistics objects in various functional areas within the logistics park multimodal transport facilities, which is affected by the work flow[3]. It not only reflects the relationship between among functional areas, but also entire operating process of the multimodal transport facilities in the logistics park.

\section{Auxiliary Services S}

In the multimodal transport facilities layout planning of Logistics Park, Service Department S means other work units except logistics operation units. It is mainly used to provide support and protection for logistics services, display transactions and so on. To some extent, it affects the 
efficiency of multimodal transport facilities in Logistics Park. Therefore, it is also an element to be considered as it may affect the layout planning[3].

\section{Logistics Operation Technology T}

Logistics operation technology includes the general principles of equipment and technology in logistics activities, the theory of natural and social science used in logistics activities. Logistics operation technology mainly refers to all kinds of logistics operation equipmentin the logistics park multimodal transport facilities layout. The level of technology directly impacts the number of equipment and technicians, the size of the operating area, efficiency, cost and others, thereby affecting the layout results. Therefore, it requires sufficient attention on logistics operation technology $\mathrm{T}$ while planning the layout of multimodal transport facilites in logistics park[3].

\section{Analysis of the Relationship between Logistics and Non Logistics}

\section{Logistics Relationship Analysis}

Usually the method of analyzing logistics relationship is determined by $\mathrm{P}$ and $\mathrm{Q}$. So the logistics relationship analysis is also called "P - Q analysis".

This article uses logistic from-to diagramming to show the logistics relationship between each functional area of logistics park. Logistic from-to diagramming is a kind of Rectangular matrix table. It is usually used to represent the source of the inter unit logistics by rows in the matrix, it is called 'from'. A list of destinations for logistics between units, it is called 'to'. And line crossing points indicate the amount of logistics from the source destination.

Logistics intensity is divided into five levels by SLP, by using symbols A, E, I, 0, U to express them. Logistics intensity of these symbols decreases gradually. And it represents five kinds of logistics strength, such as the super high logistics intensity, the high logistics intensity, the larger logistics intensity, the general logistics intensity and the negligible logistics intensity[4]. The logistics intensity level corresponding to the functional area should be determined according to the proportion of the logistics route or the proportion of the logistics, as shown in Tab.1.

Tab.1 Logistics intensity grade

\begin{tabular}{|l|l|l|l|}
\hline Logistics strength grade & Symbol & $\begin{array}{l}\text { Logistics line } \\
\text { proportion(\%) }\end{array}$ & $\begin{array}{l}\text { Logistics transportation } \\
\text { proportion(\%) }\end{array}$ \\
\hline Super high logistics intensity & A & 10 & 40 \\
\hline High logistics intensity & E & 20 & 30 \\
\hline Larger logistics intensity & I & 30 & 20 \\
\hline General logistics intensity & O & 40 & 10 \\
\hline Negligible logistics intensity & U & & \\
\hline
\end{tabular}

Tab.2 From-To chart of Logistics

\begin{tabular}{|l|l|l|l|l|l|l|}
\hline & $\begin{array}{l}\text { Functional } \\
\text { area 1 }\end{array}$ & $\begin{array}{l}\text { Functional } \\
\text { area 2 }\end{array}$ & $\begin{array}{l}\text { Functional } \\
\text { area3 }\end{array}$ & $\begin{array}{l}\text { Functional } \\
\text { area4 }\end{array}$ & $\begin{array}{l}\text { Functional } \\
\text { area5 }\end{array}$ & $\ldots . .$. \\
\hline Functional area 1 & & & & & & \\
\hline Functional area 2 & & & & & & \\
\hline Functional area 3 & & & & & & \\
\hline Functional area 4 & & & & & & \\
\hline Functional area 5 & & & & & & \\
\hline$\ldots . .$. & & & & & & \\
\hline
\end{tabular}

In order to clearly reflect the logistics relationship between among all the functional areas in the multimodal transport facilities system of logistics park, it can be used to express logistics from-to diagramming. That is, in a rectangular matrix table rows, columns list all the functional partition(Physical and virtual function areas), and in the rows and columns in the intersection of the grid to fill in the functional areas and functional areas of the logistics level of intensity, so as to get the logistics park multimodal transport system logistics from table to table, as shown in Tab2. 
In order to be able to clearly describe the relationship between all the functional areas of the logistics, logistics tables can also be used to express the logistics intensity, as shown in Fig.1.

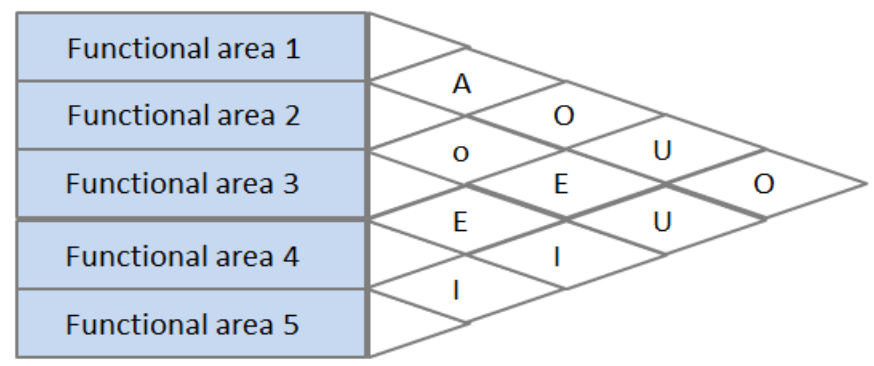

Fig.1 Logistics relationship diagram

\section{Non Logistics Relationship Analysis}

Logistics Park multimodal transport facilities layout of the non logistics relationship can be considered from in the following four aspects:

1) Organizational relationship: refers to the organizational relationship between the various functional areas;

2) Program relationship: through the logistics, information flow to establish the link;

3) Environmental relationships: keep the relationship between functional areas because security.

4) Functional relationship: the area should be closely arranged because of the same function or relevance.

This paper analyzes the non logistics relationship between each functional area by using the non logistics relationship graph. By evaluating non logistics related degree, and using the symbol A,E,I,O,U,X, it can be shown that every function area's degree of closeness ${ }^{[4]}$. The qualitative analysis level of non logistics relation is shown in Tab.3, and reasons for the evaluation grade of non logistics relation grade table are shown in Tab.4.

Tab.3 The Classification of Non-Logistics Connections

\begin{tabular}{|l|l|l|l|}
\hline Symbol & Score & Degree of closeness & Proportion(\%) \\
\hline A & 4 & Absolutely important & $2-5$ \\
\hline E & 3 & Very important & $3-10$ \\
\hline I & 2 & Important & $5-15$ \\
\hline O & 1 & Generally important & $10-25$ \\
\hline U & 0 & Unimportant & $45-80$ \\
\hline X & -1 & Negative degree of closeness & Don't want to approach \\
\hline
\end{tabular}

Tab.4 The Reasons for Classification of Non-Logistics

\begin{tabular}{|l|l|}
\hline Reason code & Reason \\
\hline 1 & Work-flow continuity \\
\hline 2 & Material handling \\
\hline 3 & Production service \\
\hline 4 & Use the same facilities \\
\hline 5 & Common space \\
\hline 6 & The frequent degree of people contact \\
\hline 7 & Noise, dust, vibration and other environmental health \\
\hline 8 & Easy to manage \\
\hline
\end{tabular}

After determining the degree of non logistics relationship of each functional area, It can create an establishment of the non logistics relation map. In the upper part of each rhombus sash with rank symbol close degree, the lower part of the digital representation of determine the close degree to the reason. As shown in Fig.2. 


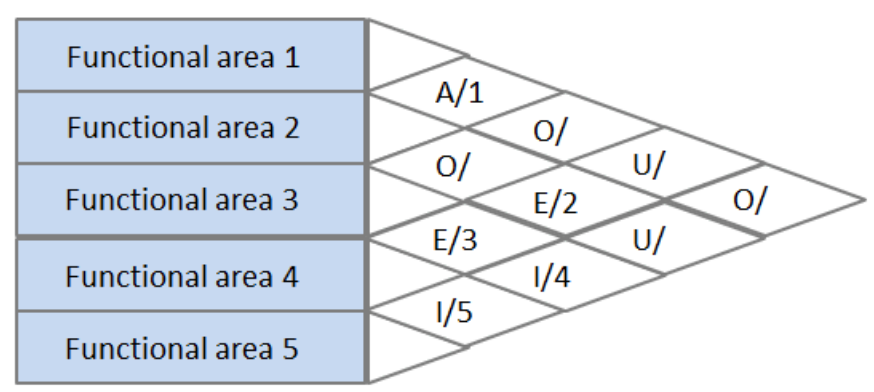

Fig.2 Non-Logistics relationship diagram

\section{Comprehensive Correlation Analysis}

Because of the logistics park of multimodal transport facilities, there are both relationship between logistics and non-logistics. At this time, during layout planning, it requires to combine comprehensive analysis of the logistics and the non-logistics, integrate these two factors, drawing comprehensive relational tables, and then to realize each function of reasonable layout according to the comprehensive relationship . When drawing a comprehensive relationship table, the following steps should be taken on the basis of the logistics relationship table and the non-logistics relationship table:

(1)Through the logistics analysis, obtain the logistics quantity among each operating units and mutual relations of those units on the basis of rationalization of logistics.

(2)Determine the logistics relationships between each operation department mutual influence factors and levels, make the operation department relationship table;

(3)Determining the correlated importance of the relationship between logistics and non-logistics. Usually this correlated importance weight ratio m: $n$ between 1: 3 to 3: 1 . In reality, according to the relative importance of the relationship between logistics and non-logistics, the ratio of $\mathrm{M}: \mathrm{n}=1: 1$ : 2: $1: 1: 1: 2,1: 3$, this ratio is called the weighted value.

(4)Quantify the intensity level of logistics and non-logistics. Usually numerical these quantification for $\mathrm{A}=4, \mathrm{E}=3, \mathrm{I}=2, \mathrm{O}=1, \mathrm{U}=0, \mathrm{X}=-1$.

(5) Calculate the quantitative relationship between the working units. Set any two operating units were $A_{i}$ and $A_{j}$, the logistics strength of the relationship between the levels of $M_{i j}$. The degree of close relationship of non-logistics is $\mathrm{N}_{\mathrm{ij}}, \mathrm{A}_{\mathrm{i}}$ and $\mathrm{A}_{\mathrm{j}}$ between the unit of the comprehensive degree of close relationship between $\mathrm{C}_{\mathrm{ij}}$ : $\mathrm{C}_{\mathrm{ij}}=\mathrm{m} \times \mathrm{M}_{\mathrm{ij}}+\mathrm{n} \times \mathrm{N}_{\mathrm{ij}}$.

6) Comprehensive classification of correlation degree. The classification of the comprehensive relationship is the same as A, E, I, O, U, X, and the value of each level is decreasing gradually. At the same time, the matching number of each operation unit should be in accordance with the conventional proportion. Tab.5 shows the level and division of the comprehensive relationship.

Tab.5 The Level Classification of Comprehensive Relationship

\begin{tabular}{|l|l|l|l|}
\hline Symbol & Close degree & Proportion(\%) & Score \\
\hline A & Absolutely necessary & $1-3$ & 4 \\
\hline E & Especially important & $2-5$ & 3 \\
\hline I & important & $3-8$ & 2 \\
\hline O & Generally important & $5-15$ & 1 \\
\hline U & Unimportant & $20-85$ & 0 \\
\hline$X$ & Don't want to be near & $0-10$ & -1 \\
\hline
\end{tabular}

(7)The relationship among functional areas of the comprehensive score is distributed into comprehensive close degree according to a certain proportion, and then the functional areas integrated relationship graph can be get, the integrated relationship among each functional areas can be visually seen from the figure above.

(8)Draw the relevant graph of the operation department position. 


\section{Summary}

This paper mainly focuses on the analysis of the relationship between logistics and non-logistics in the SLP method, and the relationship between the two with the extension. And then it explains how it works to solve the primary issue on the multimodal transport facilities layout planning in the logistics park, which may decrease the level of difficulty of the logistics park planning in the future development.

\section{Acknowledgement}

This paper is subsidized by the innovation project of graduate education (2015YJ011)on Shandong Jiaotong University.

\section{References}

[1] Lv Tong zhou. The national strategy to help push the development of intermodal [J]. China ocean shipping, 2014 (11)(In Chinese)

[2] Lv Tong zhou. To Chinese Intermodal Transportation Association -- an interview with Chinese transport branch secretary general Li Muyuan [J]. Chinese ocean shipping, 2013 (10)(In Chinese)

[3] Liu Binglian, Lin tan. The development trend of international multimodal transport and the Countermeasures of China [J]. China circulation economy, 2009 (12)(In Chinese)

[4] He Minai, Liu Tingxin. The logistics facilities and equipment [M]. Beijing: Higher Education Press, 2009.6(In Chinese) 